We are anxious that our cyclists should be properly fit and in good health before competing, and would welcome any facilities made available for appropriate examination and testing. Cramp is one of the major bugbears of cycling and we are anxious to prevent it if possible.

We are also anxious to apply wherever appropriate scientific methods to assess the potential of our cyclists, and would welcome advice and help on this matter. We are interested to know if there is any significance in biorhythms.

In conclusion, cycling is rather a cinderella among sports, and we find that we need help and guidance on a vast number of problems, including questions of the use of various foods and other substances which some may regard as dope, psychological problems, minor physical ailments and so on.

DIET IN TRAINING: dietary requirements in long distance cycling events.

Dr. E. J. Hamley, Loughborough College of Technology, Leics.

Until recently the use of specialised diets in cycling sports was limited by the inexperience of helpers available and the individuat food habits of the performers. As the record times for cycling distances longer than 200 miles improved it became obvious that more serious consideration of diet was necessary both in preparation for attempts to set new records and to provide adequate supplies of nutriment during the events. This presented a series of problems which I have studied while being associated with cyclists interested in establishing new records in the sport.

The first problem was unspecific and concerned correction of excess weight and minor nutritional deficiencies revealed during the early parts of the training programme. The second problem was to adjust water and salt intakes during events of twelve hours and longer. In such events the particular cyclists concerned imbibed liquid at rates above one pint per hour while cycling and frequently showed minor symptoms of salt depletion which were corrected by adding an amount of selt (calculated from urine analyses) to the liquid imbibed. To mask this new flavour fruit juices and sugar were added. The third problem was to ensure that the intake of solids while cycling would be limited to easily absorbed precooked focds of high carbohydrate and low residue contents such as porridges and cream crackers. In organising the feeding arrangements for events lasting 24 hours and longer - such as when distances up to 1000 miles are cycled in $2 \frac{1}{2}$ days - the amount of food and liquid required had to be estimated and apportioned along the route. In the absence of adequate energy 
calculations on the individual performers, their previous experience of food consumed in events lasting 24 hours and the value $-700 \mathrm{k} \cdot \mathrm{cal} / \mathrm{h}$ obtained from published estimates of highest work activity, seemed to indicate that a dietary allowance of $1000 \mathrm{k}$.cal $/ \mathrm{hr}$. of cycling time might be reasonable. This figure, which obviously allowed an excess, was found useful in preparing the diets for several events when new records were established for cycling 1000 miles and for the journey between John o'Groats and Land's End. Similar events cycled in France have confirmed the use of this figure.

\section{THE ANNUAL GENERAL MEETING}

Report on the Eleventh Annual General Meeting of the British Association of Sport and Medicine, held at the London School of Hygiene and Tropicall Medicine at $5.30 \mathrm{p.m}$. on the 19th October, 1963, there being present 50 Members of the Association.

In the unavoidable absence of Sir Arthur Porritt, the Chair was taken by Mr. W. E. Tucker.

1) The minutes of the last Annual General Meeting were read, approved and signed.

2) The Honorary Secretary's Report was given and approved.

3) The Honorary Treasurer's Report on the accounts was given. The balance sheet which had already been circulated by post to Members, was approved.

4) Election of Officers. The Honorary Secretary informed the meeting that the Executive Committee submitted themselves for re-election en bloc for a period of one year only. This was to facilitate the re-drafting of the Constitution and Bye-Laws of the Association at present in progress. The rapid expansion in membership and activities of the Association had rendered necessary a re-organisation of the administrative structure. This re-organisation is to be reflected in the new Bye-Laws and Constitution. The Executive Committee wished to continue in 